\title{
BMJ Open Study protocol for a double-blind, randomised placebo-controlled trial evaluating clinical effects of platelet- rich plasma injection for acute grade-2 hamstring tear among high performance athletes
}

\author{
Mohamad Shariff A Hamid (D) ,1,2 Kamarul Hashimy Hussein, ${ }^{2}$ \\ Ahmad Munawwar Helmi Salim, ${ }^{2}$ Arshad Puji, ${ }^{3}$ Rosnah Mat Yatim, ${ }^{2}$ \\ Chin Chee Yong, ${ }^{2}$ Thomas Wong Yong Sheng ${ }^{2}$
}

To cite: A Hamid MS, Hussein KH, Helmi Salim AM, et al. Study protocol for a double-blind, randomised placebo-controlled trial evaluating clinical effects of platelet-rich plasma injection for acute grade-2 hamstring tear among high performance athletes. BMJ Open 2020;10:e039105. doi:10.1136/ bmjopen-2020-039105

- Prepublication history and additional material for this paper are available online. To view these files, please visit the journal online (http://dx.doi. org/10.1136/bmjopen-2020039105).

Received 07 April 2020 Revised 15 June 2020 Accepted 13 July 2020

A) Check for updates

(C) Author(s) (or their employer(s)) 2020. Re-use permitted under CC BY-NC. No commercial re-use. See rights and permissions. Published by BMJ.

For numbered affiliations see end of article.

Correspondence to Dr Mohamad Shariff A Hamid; ayip@um.edu.my

\section{ABSTRACT}

Introduction Hamstring injury among athletes often results in significant morbidity. Currently, there are controversies regarding the clinical use of platelet-rich plasma (PRP) for the treatment of acute hamstring injury. Methods and analysis This study is a single-centre double-blind randomised placebo-controlled trial. Sixty-eight patients will be randomised to receive under ultrasound guidance either a single injection of leucocyte-rich PRP (LR-PRP) or normal saline. All patients will undergo a standardised hamstring rehabilitation programme under the supervision of a sports physiotherapist. Outcome data will be collected before intervention (baseline), and thereafter on a weekly basis. The primary outcome measure is the duration to return-toplay. It is defined as the duration (in days) from the date on which the injury occurred until the patients were pain-free, able to perform the active knee extension test and have regained hamstring muscle strength. Secondary outcome measures include assessment of pain intensity and the effect of pain on to day-to-day functions using the selfreported Brief Pain Inventory - Short Form questionnaire. Both the primary and secondary outcomes were assessed at baseline and thereafter once a week until return to play. Also, hamstring injury recurrence within the first 6 months after recovery will be monitored via telephone. The results of this study will provide insights into the effect of LR-PRP in muscle and may help to identify the best PRP application protocol for muscle injuries.

Ethics and dissemination Ethics approval were obtained from the Medical Research Ethics Committee of the University of Malaya Medical Centre. Results of this trial will be submitted for publication in a peer-reviewed journal.

Trial registration number ISRCTN76844299.

\section{INTRODUCTION}

Hamstring injuries are one of the most common muscle lesions in many sports
Strengths and limitations of this study

A double-blind randomised parallel group design is a rigorous design to address the research question.

- Findings from this study could contribute to optimal platelet-rich plasma application for treating grade-2 muscle injuries.

- Findings from this study should not be generalised to other athletes because the patients in this study are national level athletes with frequent and regular access to supervised rehabilitation sessions at the National Sports Medicine Centre.

including soccer, American football, Australian rules football and athletics. ${ }^{1-5}$ Previous studies have recorded hamstring injury prevalence ranging from $23 \%$ to $50 \%$ of muscle injuries in sports. ${ }^{6-8}$ In most instances, a hamstring injury is caused by indirect trauma associated with non-contact activities that require sprinting, jumping and ballistic movements of the lower limb. ${ }^{68}$ Performing these movements requires the hamstring muscle to eccentrically contract and develop tension while lengthening. ${ }^{9}$

Muscle injury diagnosis and grading are usually made through a detailed history and physical examination. ${ }^{1}$ Additionally, radiological imaging, including ultrasonography and MRI, is commonly used to confirm diagnosis. ${ }^{3}$ Hamstring injury could be classified based on clinical and radiological evaluations depending on the severity of the affected muscle fibres as well as the position of the injury along the hamstrings muscle (eg, muscle belly, myotendinous junction or proximal tendon). The characteristics of 
hamstring injuries could be useful in predicting the duration of recovery. ${ }^{10-14}$

Despite its frequent occurrence, the best treatment for muscle injury is not yet clearly defined. Various interventions have been suggested by previous researchers. ${ }^{5}{ }^{15-17}$ In the acute phase (up to first 72 hours following muscle injuries), the treatment objectives include to limit the extent of injuries, minimise swelling and control pain. These are often achieved through protection, rest, ice, compression and elevation of the injured area. ${ }^{18}$ These approaches are usually combined with a short course of non-steroidal anti-inflammatory drugs (NSAIDs) and rehabilitation programme. ${ }^{5}$

In professional sport, muscle injury often leads to severe pain and disability, resulting in loss of training and competition time. Despite various treatment methods, the duration to return-to-play (DRP) varies from 6 weeks to never, with significant variation depending on injury severity. ${ }^{5-7} 1619$

With the increasing understanding of basic sciences of muscle healing, scientists and clinicians are exploring on autologous platelet-rich plasma (PRP) to accelerate recovery. PRP contains a myriad of growth factors that are released into the injured area. Growth factors including platelet-derived growth factors, vascular endothelial growth factors, epidermal growth factors, fibroblasts growth factors (FGFs), insulin-like growth factor-1 (IGF-1) and tumour growth factor- $\beta 1$ (TGF- $\beta 1$ ) enhance myoblast proliferation and differentiation. ${ }^{16}$

The abundance of growth factors and cytokines in PRP is believed to have the ability in accelerating muscle healing by induction of stem cells proliferation and migration, increased angiogenesis and tissue regeneration. ${ }^{20-22}$

Sanchez et al reported athletes diagnosed with small muscle tears receiving PRP injection achieved full recovery within half of the expected time. ${ }^{23}$ Wright-Carpenter et al demonstrated that autologous-conditioned serum injected into damaged muscle reduced the length of professional sportsmen's full return-to-play (RTP) by $30 \%$ (6 days). They attributed the observed effects on the presence of increased levels of growth factors (FGF-2, Hepatocyte Growth Factor and TGF- $\beta 1$ ) demonstrable on ELISA. $^{19}$

To date, only four randomised-controlled trials (RCTs) on the effect of PRP on hamstring muscle injuries have been published. Of these only two studies reported significantly earlier RTP in athletes treated with PRP compared with control. ${ }^{24}{ }^{25}$ In two other studies, there were no differences in the DRP between PRP-treated patients and controls. ${ }^{26-28}$ Inconsistencies between studies could be due to several factors including variations in the severity of hamstring injuries. All these RCTs included patients with acute hamstring injuries, however, the severity of injury differs across studies. Studies with grade-2 hamstring injury reported significantly faster recovery ${ }^{24}{ }^{25}$ whereas studies that recruited participants with grade-1 and grade-2 hamstring injuries did not report any significant difference between PRP and control group. ${ }^{27} 28$ The PRP preparation techniques affect the type of PRP produced and its cellular contents (eg, number of platelets, white blood cells (WBCs) and red blood cells (RBCs)) which could potentially affect the clinical outcome. ${ }^{29}$ Two studies used leucocyte-rich PRP (LR-PRP), ${ }^{24} 28$ one study used autologous-conditioned plasma ${ }^{27}$ and the type of PRP was not reported in the other study. ${ }^{25}$ Current RCTs also vary in terms of the injection techniques. PRP injection procedure was performed under ultrasound guidance in three studies. ${ }^{24} 25$ In one study, PRP injection was performed without radiological guidance (landmark-guided technique) ${ }^{28}$ Ultrasound-guided injection was reported to be more accurate than landmark-guided injections in delivering injectants into the injured area. ${ }^{30}$ The type of controls also varies between the RCTs. In two studies, the outcome of PRP injection was compared with a standard rehabilitation program. ${ }^{24}{ }^{25}$ One study compared PRP with normal saline (NS) injection. ${ }^{27}$ The other study was a three-arm study which examined the effect of PRP, Platelet Poor Plasma and a standard hamstring rehabilitation program. ${ }^{28}$

There is still debate over the use of PRP for acute muscle injuries. ${ }^{31-34}$ Current systematic reviews reported there are limited RCTs that evaluated the effects of PRP on acute hamstring injury. ${ }^{35-37}$ Furthermore, the available evidence is considered to be very low to moderate quality due to risk of bias, inconsistency and imprecision of the study protocols. Hence, there is inadequate evidence to support PRP for acute hamstring injury in clinical practice. More studies using robust clinical design are recommended to shed further light on PRP use for acute muscle injuries. ${ }^{35} 37$

Our recent review through trial registries databases (including ISRCTN, ANZCTR, EU clinical trials register, UMIN-CTR and Clinical.gov registries) using 'plateletrich plasma and hamstring' as keywords did not find any ongoing trial or recently registered study protocol and except for the current study.

This report describes the protocol of a double-blind, randomised placebo-controlled trial to determine the clinical effects of PRP versus NS injection on the DRP for the treatment of a grade-2 hamstring injury among high performance athletes. We hypothesised that the presence of growth factors in the PRP could accelerate muscle healing resulting in earlier RTP.

\section{METHODS AND ANALYSIS \\ Study design}

This study is a randomised, double-blind, placebocontrolled trial conducted at the National Sports Medicine Centre (NSMC), Kuala Lumpur, Malaysia. The study protocol abides to the guideline established by the Standard Protocol Items: Recommendations for Interventional Trials (online supplementary appendix 1). The NSMC provides healthcare services exclusively to national athletes, at both the competitive and developmental levels. Patients diagnosed with grade-2 hamstring muscle 
injury will be randomised to receive either a single PRP or NS injection into the injured site under ultrasound guidance. Following the intervention, all patients will be reassessed every week until full recovery achieved. The duration to full recovery between the two groups will be used as the primary outcome measures on the effectiveness of the intervention.

\section{Patients}

Patients with ultrasonography confirmed diagnosis of grade-2 hamstring will be invited to participate in this study. Notice of study and invitation to participate in this study will be distributed to all sports physicians and medical officers at the NSMC. The eligibility criteria for inclusion in this study are listed below.

Inclusion criteria:

1. Aged 18 years and above.

2. Diagnosed with acute ( $\leq 7$ days) grade-2 hamstring injury based on clinical assessment and confirmed on ultrasonography.

3. Understand and willing to follow the study protocol and had completed the written informed consent form.

Exclusion criteria:

1. Had undergone some form of injection therapy for the current injury.

2. Use of NSAIDs within 1 week of randomisation.

3. Unable to fulfil weekly follow-up appointments and comply with the rehabilitation programme.

4. Significant cardiovascular, renal, hepatic disease, malignancies, history of anaemia and previous muscle surgery.

\section{Procedures}

The summary of this trial is outlined in figure 1. Patients referred to the NSMC with suspected hamstring injury will be screened for eligibility. An experienced sports physician (KHH) will conduct all screening process which includes clinical physical examination and preliminary ultrasound assessment. Following these, a grading of injury severity will be determined as recommended by previous studies. ${ }^{138}$ Potential patients will then undergo diagnostic ultrasonography assessment conducted by a sports physician (MSAH/AP) with more than 10 years of diagnostic musculoskeletal ultrasound experience. All diagnostic ultrasound assessment will be performed using the Philips EPIQ5 Diagnostic Ultrasound System using 18 $\mathrm{MHz}$, linear probe to confirm the diagnosis. The severity of hamstring injury will be graded using the radiological ultrasound grading system (table 1) used by Hamid et $a .^{22}$ Diagnostic ultrasound assessment will be performed within the first 48 hours of completion of the physical assessment. All ultrasonography findings will be documented in a standard ultrasound report form (online supplementary appendix 2).

Patients diagnosed with acute grade-2 hamstring injury based on clinical and confirmed by diagnostic ultrasound will be invited to participate in the study. All

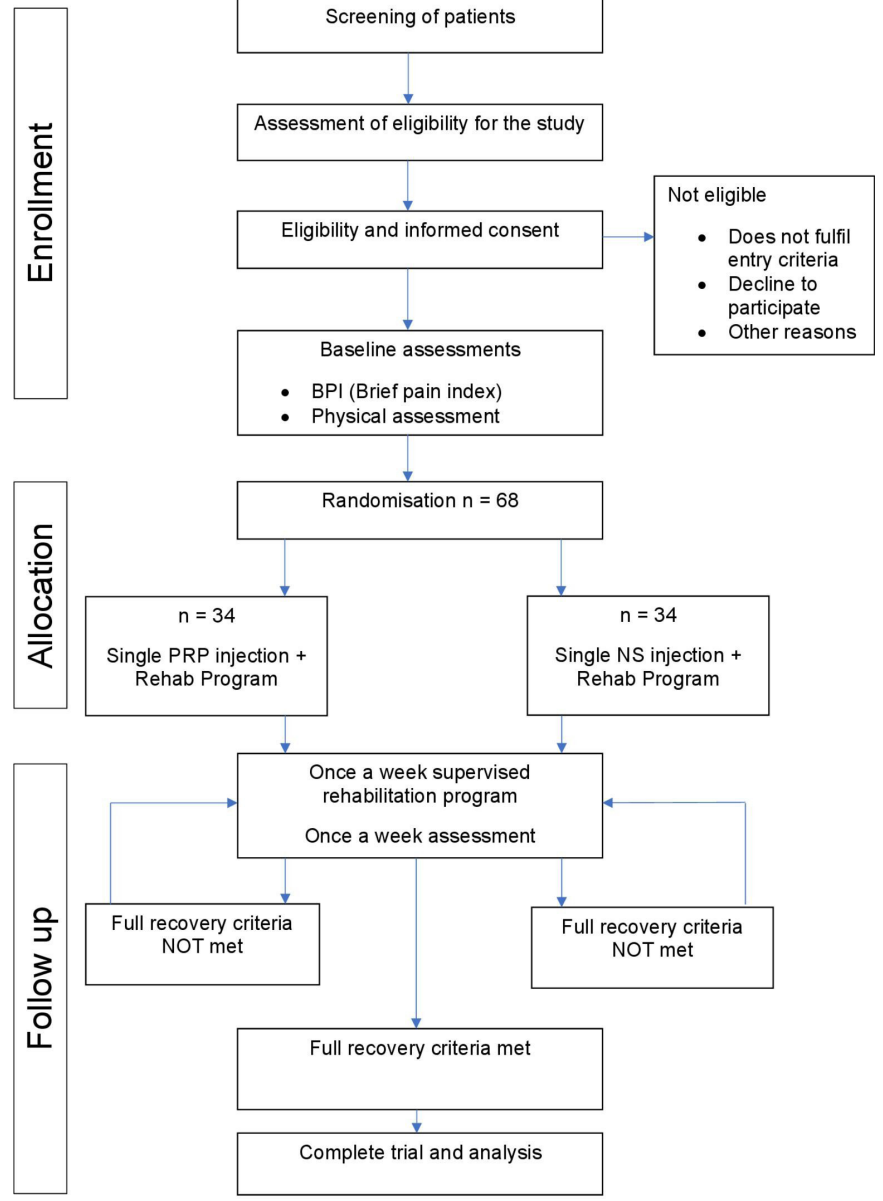

Figure 1 Study flowchart. NS, normal saline; PRP, plateletrich plasma.

eligible subjects will be given information about the study, including study procedures via the patient's information sheets (online supplementary appendix 3). All patients will be required to provide verbal and written consents before randomisation.

\section{INTERVENTIONS}

\section{PRP group}

Patients randomised to this group will receive a single $3 \mathrm{~mL}$ injection of PRP into the injury site under ultrasound guidance administered by a sports physician (MSAH/AP). The PRP will be prepared using a commercial kit, GPS III Systems (Biomet Biologics, Warsaw, Indiana, USA). The injection will be administered once after randomisation of the patient (day 1 of the study).

\section{PRP preparation}

Fifty-six millilitres of venous blood will be extracted from the antecubital vein of all patients. Fifty-four millilitres of the blood will be transferred into a $60 \mathrm{~mL}$ syringe containing $6 \mathrm{~mL}$ of anticoagulant-acid citrate dextrose solution A (ACD-A). Two millilitres of the blood collected will be sent to the laboratory for full blood count analysis, including RBC, platelet and WBC quantification. Blood extraction and PRP preparation will be performed by two 
Table 1 Grading of muscle strain based on ultrasound appearance $^{22}$

\begin{tabular}{ll}
\hline Grade & Ultrasound findings \\
\hline 0 & $\begin{array}{l}\text { No ultrasound features seen } \\
\text { Muscle oedema only }\end{array}$ \\
\hline $2 a$ & $\begin{array}{l}\text { Partial tears of muscle fibres, disruption } \\
\text { involving }<33 \%\end{array}$ \\
\hline $2 b$ & $\begin{array}{l}\text { Partial tears of muscle fibres, disruption } \\
\text { involving } \geq 33 \%-66 \%\end{array}$ \\
\hline $2 c$ & $\begin{array}{l}\text { Partial tears of muscle fibres, disruption } \\
\text { involving } \geq 66 \%-99 \% \\
3\end{array}$ \\
\hline
\end{tabular}

staff nurses in accord with the manufacturer guideline. All procedures will be conducted in a treatment room at the NSMC. As an acidic anticoagulant (ACD-A) was added during collection, PRP will be buffered to increase the $\mathrm{pH}$ to normal physiological levels before injection by adding $8.4 \%$ sodium bicarbonate solution in a ratio $0.05 \mathrm{~mL}$ of sodium bicarbonate to $1 \mathrm{~mL}$ of PRP as indicated by the manufacturer. No activating agent will be added to the PRP throughout the process. The time taken to prepare PRP will be about $30 \mathrm{~min}$. Approximately $6 \mathrm{~mL}$ of PRP could be produced by a $60 \mathrm{~mL}$ GPS III kit. Three millilitres of the PRP will be injected into the injured area under ultrasound guidance using aseptic technique. One millilitres will be sent to the NSMC laboratory for platelets and leucocyte counts. The remaining $2 \mathrm{~mL}$ of PRP will be stored at $-80^{\circ} \mathrm{C}$ and sent to a private laboratory on study completion for quantification of growth factors including basic FGF, IGF-1 and TGF- $\beta 1$.

\section{NS group}

Patients in the NS group will undergo precisely the same procedure as those in the PRP group. The only difference being patients in this group will receive a single 3 $\mathrm{mL}$ injection of NS administered under ultrasound guidance using aseptic technique. Meanwhile, the remaining $54 \mathrm{~mL}$ of blood collected from patients in the NS group will be used to evaluate a cost-effective technique of PRP preparation (without commercial kit) using consumables readily available at the NSMC. The PRP prepared using this method will also be sent to the laboratory for analysis of cellular and growth factors components.

\section{Injection technique}

All injection will be performed in the ultrasound room at the NSMC using aseptic technique (ultrasound probe cover, sterile ultrasound gel). Both the PRP and NS will be prepared in a syringe and covered with an opaque tape to ensure that the content of the syringe is not known to the patient. Patients will be placed in the prone position and will be requested not to turn their head during the procedure. The injection site will be cleaned with $10 \%$ povidone-iodine and spirit solutions before administration. No local anaesthetic agent will be administered during the intervention. Under ultrasound guidance, $3 \mathrm{~mL}$ of injectants (PRP or NS) will be delivered directly into the injured area via a $22 \mathrm{G}$ ultrasound needle. Patients in both groups will only receive a single injection throughout the study.

Following injection of either PRP or NS, cryotherapy will be applied for $15 \mathrm{~min}$. Patients will be advised to rest the injected area for the next 48 hours. Patients will be asked to avoid taking NSAIDs; however, the use of oral paracetamol and ice will be allowed. Patients will be asked to record all medication used.

\section{REHABILITATION PROGRAM}

All patients will undergo a standardised hamstring rehabilitation programme supervised by a sports physiotherapist (RMY/CCY). Rehabilitation sessions commenced on the third day (72 hours) following injection. The rehabilitation protocol prescribed was based on a programme previously described by Erikson and Sherry. This rehabilitation protocol (online supplementary appendix 4) is based on current evidence, that integrates the progressive agility trunk stabilisation and progressive running and eccentric strengthening components. ${ }^{31}$ Patients will undergo daily (five times/week) supervised sessions conducted at the NSMC physiotherapy unit until full recovery is achieved. All rehabilitation sessions will be recorded in the patient's rehabilitation logbook by the physiotherapist in charge.

\section{SAMPLE SIZE}

The sample size was determined using the G*power software (V.3.1.9.2, Heinrich Heine, Universitat Desseldorf). In this study, the sample size was estimated using DRP, and SD results from a previous study. Previous study found DRP of 26.7 (7.0) days among patients who received PRP and 42.4 (20.6) days among those treated with rehabilitation programme alone. ${ }^{24}$ Taking into account an attrition rate of $30 \%$, and a study power of 0.95 , a sample size of 34 patients per group was estimated. Hence a minimum number of 68 patients will be required for this study.

\section{RANDOMISATION}

Randomisation will be performed when patients agreed to participate and signed the written informed consent form. Computer-generated block randomisation of eight was used to create a randomisation schedule (www.randomization.com). The randomisation schedule was performed and kept by a research member (AMHS) not involved in the intervention process. Following confirmation of participation, the treatment assignments will be revealed to the physician who will be performing the injection. Subjects 
will be randomised into either (1) autologous PRP injection or (2) NS.

\section{BLINDING}

Two sports physiotherapists (RMY and CCY) will be involved in providing rehabilitation programme and act as outcome measures assessors. Both physiotherapists attended a half-day workshop (June 2019) conducted by the primary researcher (MSAH) to ensure consistency in providing rehabilitation programme as well as on outcome measure assessments. Both physiotherapists will be blinded to patients group allocation. In this study, patients will also be blinded to the treatment they received. All patients will undergo similar study procedures, including extraction $56 \mathrm{~mL}$ of venous blood from the patients' arm. Patients differ only on the type of injection they received. To ensure blinding, patients will be positioned in prone throughout the intervention and requested not to turn their head to the back during the procedure. On trial completion, physiotherapists and patients were asked to guess which treatment each participant had received. The success of blinding was determined using the 'blinding index' as described by James et $a l^{39}$

\section{OUTCOMES}

\section{Patients characteristics}

Patients sociodemographic information, including gender, date of birth, ethnic background, sport and level of participation, will be recorded. Additionally, information related to the injury such as date of injury onset, mechanism of injury, the situation when the injury occurred (training, competition or others) and history of previous injury/ies will be documented.

\section{Primary outcome measures}

The primary outcome of this study is the DRP. DRP is defined as the duration (in days) from the date on which the injury occurred until the patients met the RTP criteria. Since there are limited scientific studies examining the outcome of various RTP strategies, ${ }^{17} 32$ it is necessary to set the criteria for RTP. The RTP criteria used in this study (table 2) were based on recommendations of clinical sports medicine practitioners. ${ }^{53344041}$

\begin{tabular}{ll}
\hline Table 2 & Criteria for return-to-play \\
\hline Sign & General recommendation \\
\hline Pain & Pain-free (on direct palpation) \\
& $\begin{array}{l}\text { Pain-free on hamstring contraction (resisted } \\
\text { isometric hamstring muscle contraction) }\end{array}$ \\
Active knee & $\begin{array}{l}\leq 10^{\circ} \text { difference between injured and non- } \\
\text { injured leg }\end{array}$ \\
extension & $\begin{array}{l}\text { Isokinetic strength within } 5 \%{ }^{48} \text { to } 10 \%{ }^{5} \text { of } \\
\text { Ctrength }\end{array}$ \\
\hline
\end{tabular}

Outcome assessments will be performed once a week by the physiotherapist in charge (RMY/CCY). At each visit, patients will complete the Brief Pain InventoryShort Form (BPI-SF) questionnaire following this the physiotherapist will clinically evaluate patient's recovery progress and recorded in the patients' clinical research form.

Clinical evaluation includes:

1. General inspection of the injured area for bruising, swelling or any other abnormalities.

2. Palpation for any tenderness of the affected area. The assessor will document the distance of the maximal area of tenderness from the ischial tuberosity.

3. Active knee extension (AKE) test for hamstring range of movement assessment. The AKE test is an active test that is safe as the participant dictates the endpoint and has been recommended and often used to measure hamstring tightness. ${ }^{42}$

4. Hamstring pain provocation test. In the prone position, patients are asked to flex (bend) the knee at approximately $15^{\circ}$ and maintain the position while the assessor provides force against flexion. The test is considered positive if patients experience pain. This test is only performed when all other assessments did not reproduce pain. ${ }^{14}$

Patients will be allowed to resume sporting activities only when they have met the criteria as described in table 2.

\section{Secondary outcome measures}

Brief Pain Inventory-Short Form

The BPI-SF is a self-reported questionnaire for determining pain intensity and the effect of pain on to dayto-day functions. The BPI has been validated in over three dozen languages by examining the consistency of pain severity and the impact of pain on individual. ${ }^{434}$

\section{Hamstring injury recurrence}

Patients will be contacted by telephone every month for the first 6 months after full recovery. Patients will be advised to consult the NSMC should any symptoms appear. In this study, hamstring injury recurrence is defined as an injury at the same site within the first 6 months of RTP. ${ }^{40}$

\section{Other outcomes}

\section{PRP characteristics}

The PRP prepared in this study will be classified according to the current classification system described in literature. ${ }^{45} 46$ The number of platelets present in venous blood and PRP will be determined using the high performance automated haematology analyser Sysmex XN-10 and XN-20 (Sysmex Co, Chuo-ku, Japan) at the NSMC clinical laboratory. The ratio of platelet levels in venous blood to PRP will be determined as calculated to assess the ability of GPS III kit (Biomet Biologics) to concentrate platelets. Also, the number of leucocytes present in PRP was determined using a similar method. 
Adverse effects

Patients will be asked to report any adverse effects directly or indirectly related to the intervention received at each weekly follow-up session. Similarly, the attending physiotherapists will document any adverse effects during the rehabilitation programme. The attending physiotherapist will report all adverse effects in the next research team meeting.

\section{DATA COLLECTION AND MANAGEMENT}

Data will be collected from patients at baseline, and weekly by the physiotherapist in charge until patients fulfilled the RTP criteria. Patients who had fully recovered (RTP criteria fulfilled) and allowed to resume preinjury sports activities will be contacted via telephone call on a monthly basis for the first 6 months to monitor injury recurrence. All data collected will be stored securely in a locked cabinet throughout the trial. To ensure confidentiality, each patient will be given a trial identification number. Data entry and coding will be performed by trained staff at the NSMC.

\section{STATISTICAL ANALYSIS}

The principle of intention-to-treat (ITT) will be applied for the primary outcome variable. The ITT analysis includes data that are incomplete and data from patients who had deviated from the study protocol. Multiple imputation methods will be used in handling any missing data. The DRP between groups will be compared using either the parametric (t-test) or non-parametric test (MannWhitney $\mathrm{U}$ test) based on the data distribution assessed with Shapiro-Wilk test.

Additionally, the survival analysis statistical procedure will be chosen to compare treatment effects over time (Kaplan-Meier product-limit estimator). Secondary outcome measures, including BPI-SF scores of pain severity and pain interference over time, will be evaluated using linear mixed-model analysis. All statistical analysis will be performed using the SPSS V.25.0 (SPSS), and a p value of $<0.05$ will be considered to be significant.

\section{PATIENT AND PUBLIC INVOLVEMENT}

The design of the current study was based on previous single-blinded RCT performed in recreational athletes. The current study design and protocol was further refined through discussion with several NSMC healthcare providers which include sports physicians, athletic trainer and physiotherapists. Patients were not involved in the design of the study, participants recruitment or in the determination of the outcome measures in the current trial. Study notices were distributed to sports physicians and sports associations/organisations located in the Klang Valley in the state of Selangor and the Federal Territory of Kuala Lumpur. The burden of trial interventions will be assessed by monitoring of adverse events of the interventions. Information on patient satisfaction with treatment will be collected through an online self-rating questionnaire at study completion. Results from this trial will be communicated at scientific conferences, and we also intend to publish our findings in a peer-reviewed journal.

\section{ETHICS AND DISSEMINATION}

The study was approved by the Medical Research Ethics Committee of the University of Malaya Medical Centre (MREC ID: 20166-2533) and adhere to the declaration of Helsinki. This trial was registered at the National Medical Research Register (NMRR-16-2266-32005) and the Current Controlled Trials. Participation is strictly voluntary, and potential patients will be made aware of all procedures involved in the trial via the patient's information sheets. Patients will be required to sign the informed consent form before participation. At any time, patients may withdraw from the study. Results from this trial will be communicated at scientific conferences, and we also intend to publish our findings in a peer-reviewed journal. Any amendments to the study protocol will be submitted to the Medical Research Ethics Committee of the University of Malaya Medical Centre and registered at Current Controlled Trials (https://www.isrctn.com/) and published in the RCT report.

\section{PERSPECTIVES OF THE STUDY}

Currently, available controlled clinical trials on PRP use for muscle injuries are marred with inconsistencies in various aspects which could affect the study outcome. Standardising the type of PRP used in clinical trials and the specific condition for which the intervention is targeted would allow a more definite and more substantial conclusion to be made. In this trial, the effect LR-PRP for hamstring injury will be investigated. A single ultrasound-guided LR-PRP injection will be compared with NS injection (placebo) among patients with an acute grade-2 hamstring injury. The primary outcome measure is the DRP. The RTP criteria used in this study were based on recommendations by experts and reflect current clinical practice. ${ }^{1947}$ In addition to the intervention received, patients in both groups will be required to complete a standard hamstring rehabilitation programme under the supervision of a sports physiotherapists at the NSMC. The results of this double-blind, randomised placebocontrolled trial study will shed more insights into the effect of PRP injection for treating grade-2 hamstring injuries.

\section{TRIAL STATUS}

Recruitment started on 3 September 2019, and the study was initially expected to be completed on 31 December 2021. However, recruitment of study patients had to be temporarily suspended from 18 March 2020 with the 
development of the movement control order (MCO) amid the COVID-19 pandemic. Data collection will recommence once the MCO is lifted. We plan to continue data collection for another 6 months after the last recruited patient to explore injury recurrence among patients.

\section{Author affiliations}

${ }^{1}$ Sports Medicine, Universiti Malaya, Kuala Lumpur, Wilayah Persekutuan, Malaysia ${ }^{2}$ Division of Sports Medicine, National Sports Institute of Malaysia, Kuala Lumpur, Wilayah Persekutuan, Malaysia

${ }^{3}$ Department of Orthopaedic and Traumatology, Hospital Kuala Lumpur, Kuala Lumpur, Wilayah Persekutuan, Malaysia

Contributors MSAH, KHH and AP conceived the trial and led the development of intervention design, data management, statistical analysis and drafted the first version of the manuscript. RMY, CCY and TWYS designed the rehabilitation program for the trial. KHH, RMY, CCY, TWYS and AMHS, involved in patient recruitment and data collection. All authors provided valuable feedback in preparing the manuscript. All authors have read and accepted the final version of the manuscript and are accountable for all aspects of the work.

Funding This study is funded by the National Sports Institute of Malaysia (ISNRP-002-2017).

Competing interests None declared.

Patient and public involvement Patients and/or the public were not involved in the design, or conduct, or reporting, or dissemination plans of this research.

Patient consent for publication Obtained.

Provenance and peer review Not commissioned; externally peer reviewed.

Open access This is an open access article distributed in accordance with the Creative Commons Attribution Non Commercial (CC BY-NC 4.0) license, which permits others to distribute, remix, adapt, build upon this work non-commercially, and license their derivative works on different terms, provided the original work is properly cited, appropriate credit is given, any changes made indicated, and the use is non-commercial. See: http://creativecommons.org/licenses/by-nc/4.0/.

ORCID iD

Mohamad Shariff A Hamid http://orcid.org/0000-0001-9196-0442

\section{REFERENCES}

1 Järvinen TA, Kääriäinen $M$, Järvinen $M$, et al. Muscle strain injuries. Curr Opin Rheumatol 2000;12:155-61.

2 van der Made AD, Wieldraaijer T, Engebretsen L, et al. Hamstring Muscle Injury. In: Acute muscle injuries. Springer, 2014.

3 Aspelin P, Ekberg O, Thorsson O, et al. Ultrasound examination of soft tissue injury of the lower limb in athletes. Am J Sports Med 2016;20:601-3.

4 Orchard JW. Intrinsic and extrinsic risk factors for muscle strains in Australian football. Am J Sports Med 2017;29:300-3.

5 Drezner JA. Practical management: hamstring muscle injuries. Clin J Sport Med 2003;13:48.

6 Ernlund L, Vieira LdeA. Hamstring injuries: update article. Rev Bras Ortop 2017;52:373-82.

7 Shariff AH, George J, Ramlan AA. Musculoskeletal injuries among Malaysian badminton players. Singapore Med J 2009;50:1095-7.

8 Askling C, Karlsson J, Thorstensson A. Hamstring injury occurrence in elite soccer players after preseason strength training with eccentric overload. Scand J Med Sci Sports 2003;13:244-50.

9 Zarins B, Ciullo JV. Acute muscle and tendon injuries in athletes. Clin Sports Med 1983;2:167-82.

10 Cohen SB, Towers JD, Zoga A, et al. Hamstring injuries in professional football players. Sports Health 2011;3:423-30.

11 Slavotinek JP, Verrall GM, Fon GT. Hamstring injury in athletes: using MR imaging measurements to compare extent of muscle injury with amount of time lost from competition. AJR 2012;179:1621-8.

12 Robinson M, Hamilton B. Medical interventions in the management of hamstring muscle injury. Eur J Sport Sci 2014;14:743-51.

13 Wangensteen A, Guermazi A, Tol JL, et al. New MRI muscle classification systems and associations with return to sport after acute hamstring injuries: a prospective study. Eur Radiol 2018;28:3532-41.
14 Warren P, Gabbe BJ, Schneider-Kolsky M, et al. Clinical predictors of time to return to competition and of recurrence following hamstring strain in elite Australian footballers. Br J Sports Med 2010;44:415-9.

15 Copland ST, Tipton JS, Fields KB. Evidence-Based treatment of hamstring tears. Curr Sports Med Rep 2009;8:308-14.

16 Volpi P. Football traumatology: current concepts: from prevention to treatment. Springer, 2006.

17 Orchard J, Best TM. The management of muscle strain injuries: an early return versus the risk of recurrence. Clin J Sport Med 2002;12:3.

18 Brooks GP, Hergenroeder AC. Musculoskeletal injury in children and skeletally immature adolescents: Overview of treatment principles for nonoperative injuries - UpToDate [Internet], 2020. Available: https:// www.uptodate.com/contents/musculoskeletal-injury-in-children-andskeletally-immature-adolescents-overview-of-treatment-principlesfor-nonoperative-injuries/print?search=soft $\% 20$ tissue $\% 20$ injuries\& source=search_result\&selectedTitle $=3 \sim 150 \&$ usage_type $=$ default\& display_rank=3 [Accessed 10 Mar 2020].

19 Wright-Carpenter T, Klein P, Schäferhoff P, et al. Treatment of muscle injuries by local administration of autologous conditioned serum: a pilot study on sportsmen with muscle strains. Int $J$ Sports Med 2004;25:588-93.

20 Hammond JW, Hinton RY, Curl LA, et al. Use of autologous platelet-rich plasma to treat muscle strain injuries. Am J Sports Med 2009;37:1135-42.

21 Mazzocca AD, McCarthy MBR, Chowaniec DM, et al. The positive effects of different platelet-rich plasma methods on human muscle, bone, and tendon cells. Am J Sports Med 2012;40:1742-9.

22 Quarteiro ML, Tognini JRF, de Oliveira ELF, et al. The effect of platelet-rich plasma on the repair of muscle injuries in rats. Rev Bras Ortop 2015;50:586-95.

23 Sánchez M, Anitua E A. Application of autologous growth factors on skeletal muscle healing. presented at 2nd world Congress on regenerative medicine, Leipzig, Germany, 2005. Available: https://www.rejuvmedical.com/wp-content/uploads/2016/03/H5Application-of-Autologous-Growth-Factors-on-Skeletal-Musc.pdf. pdf [Accessed 10 Mar 2020].

24 A Hamid MS, Mohamed Ali MR, Yusof A, et al. Platelet-Rich plasma injections for the treatment of hamstring injuries: a randomized controlled trial. Am J Sports Med 2014;42:2410-8.

25 Rossi LA, Molina Rómoli AR, Bertona Altieri BA, et al. Does plateletrich plasma decrease time to return to sports in acute muscle tear? A randomized controlled trial. Knee Surg Sports Traumatol Arthrosc 2017;25:3319-25.

26 Reurink G. Managing acute hamstring injuries in athletes. Br J Sports Med 2017;51:614-5.

27 Reurink G, Goudswaard GJ, Moen MH, et al. Rationale, secondary outcome scores and 1-year follow-up of a randomised trial of platelet-rich plasma injections in acute hamstring muscle injury: the Dutch hamstring injection therapy study. Br J Sports Med 2015;49:1206-12.

28 Hamilton B, Tol JL, Almusa E, et al. Platelet-Rich plasma does not enhance return to play in hamstring injuries: a randomised controlled trial. Br J Sports Med 2015;49:943-50.

29 Lana JFSD, Purita J, Paulus C, et al. Contributions for classification of platelet rich plasma - proposal of a new classification: MARSPILL. Regen Med 2017;12:565-74.

30 Daniels EW, Cole D, Jacobs B, et al. Existing evidence on ultrasound-guided injections in sports medicine. Orthop J Sports Med 2018;6:23:232596711875657.

31 Erickson LN, Sherry MA. Rehabilitation and return to sport after hamstring strain injury. J Sport Health Sci 2017;6:262-70.

32 Engebretsen AH, Myklebust G, Holme I, et al. Intrinsic risk factors for acute ankle injuries among male soccer players: a prospective cohort study. Scand J Med Sci Sports 2010;20:403-10.

33 Croisier J-L. Factors associated with recurrent hamstring injuries. Sports Med 2004;34:681-95.

34 Brukner P. Hamstring injuries: prevention and treatment-an update. Br J Sports Med 2015;49:1241-4.

35 Cruciani M, Franchini M, Mengoli C, et al. Platelet-Rich plasma for sports-related muscle, tendon and ligament injuries: an umbrella review. Blood Transfus 2019;17:465-78.

36 Sheth U, Dwyer T, Smith I, et al. Does platelet-rich plasma lead to earlier return to sport when compared with conservative treatment in acute muscle injuries? A systematic review and meta-analysis. Arthroscopy 2018;34:281-8.

37 Grassi A, Napoli F, Romandini I, et al. Is platelet-rich plasma (PrP) effective in the treatment of acute muscle injuries? A systematic review and meta-analysis. Sports Med 2018;48:971-89.

38 DeLee J, Drez D, Miller MD. DeLee \& Drez's Orthopaedic Sports Medicine. Elsevier, 2010. 
39 James KE, Bloch DA, KLS in. An index for assessing blindness in a Multi-Centre clinical trial: disulfiram for alcohol Cessation-a Va Cooperative study. Wiley online library 1996.

40 Hamid MSA, MRM A, Yusof A, et al. Platelet-rich plasma [PRP]: an adjuvant to hasten hamstring muscle recovery. A randomized controlled trial protocol [ISCRTN66528592]. BMC Musculoskelet Disord 2012;13:1-8.

41 Mendiguchia J, Brughelli M. A return-to-sport algorithm for acute hamstring injuries. Phys Ther Sport 2011;12:2-14.

42 Cameron DM, Bohannon RW. Relationship between active knee extension and active straight leg raise test measurements. J Orthop Sports Phys Ther 1993;17:257-60.

43 Aisyaturridha A, Naing L, Nizar AJ. Validation of Malay brief pain inventory questionnaire to measure cancer pain. Malays $\mathrm{J}$ Med Sci 2005; $12: 1$..

44 Cleeland CS, Annals KR. Medicine AO, Singapore, 1994. pain assessment: global use of the brief pain inventory. Psycnetapaorg.
45 Dohan Ehrenfest DM, Rasmusson L, Albrektsson T. Classification of platelet concentrates: from pure platelet-rich plasma [PPRP] to leucocyte- and platelet-rich fibrin (L-PRF). Trends Bio 2009;27:158-67.

46 DeLong JM, Russell RP, Mazzocca AD. Platelet-Rich plasma: the paw classification system. Arthroscopy 2012;28:998-1009.

47 Malliaropoulos N, Papalexandris S, Papalada A, et al. The role of stretching in rehabilitation of hamstring injuries: 80 athletes followup. Med Sci Sports Exerc 2004;36:756-9.

48 Harmon K, Hanson R, Bowen J, et al. Guidelines for the use of platelet rich plasma. The International cellular medical Society, 2011. Available: http://www.cellmedicinesociety.org/attachments/ 206_ICMS\%20-\%20Guidelines\%20for\%20the\%20use\%20of\% 20Platelet\%20Rich\%20Plasma\%20-\%20Draft.pdf [Accessed $10 \mathrm{Mar}$ 2020].

49 Hamilton B, Knez W, Eirale C, et al. Platelet enriched plasma for acute muscle injury. Acta Orthop Belg 2010;76:443-8. 